\title{
The impact of inflation on the unemployment rate in Egypt: a VAR approach
}

\author{
Emad Attia Mohamed Omran ${ }^{1, *}$ and Yuriy Bilan ${ }^{1, * *}$ \\ ${ }^{1}$ Faculty of Management and Economics, Tomas Bata University in Zlin, nam. T.G. Masaryka 5555, 76-001 Zlin, Czech Republic
}

\begin{abstract}
Unemployment and inflation are among the most critical phenomena facing both developed and developing countries due to their harmful social, economic, and political effects. The Egyptian monetary policy's main objective is to maintain a low inflation rate in the medium run to keep the confidence and a high rate of investment and economic growth. At the same time, economists argue that targeting a low-rate of inflation may increase unemployment. Although the classical Philips curve indicates a trade-off between inflation and unemployment, several empirical studies have argued that the relationship between inflation and unemployment depends on the shocks' source and lagged responses. The main objective of this paper is to examine the relationship between inflation and Egypt's unemployment rate. We used time-series data from 1980 to 2019, where a vector autoregressive (VAR) model and the Impulse response function tool (IRF) were employed. The results show that inflation has a positive relationship with GDP while negatively affecting the unemployment rate.
\end{abstract}

\section{Introduction}

One of the most critical phenomena facing both developed and developing countries is unemployment due to its harmful social, economic, and political effects. The catastrophic consequences of the COVID-19 crisis have taken the global economy to a recession which caused a high unemployment rate [1]. On the other hand, inflation volatility can cause harmful effects on economic growth [2]. Therefore, keeping a low inflation rate is one of the monetary policy's primary goals in most countries [3]. Nevertheless, according to PhilipsâĂŹs curve [4], there is a tradeoff between inflation and unemployment. The main implication of this relationship is that if a country wants to keep a low inflation rate, it must accept a high unemployment rate [5]. This paper's main objective is to examine the relationship between inflation and the unemployment rate in Egypt. The research hypotheses can be formalized as follows:

H1: There is a negative relationship between inflation and the unemployment rate in Egypt.

$\mathrm{H} 2$ : There is a negative relationship between inflation and gross domestic product (GDP) in Egypt.

\section{Literature review}

Philips [4] reported a negative relationship between wage inflation and the unemployment rate in the UK. Similarly, Samuelson and Solow [6] confirmed this relationship using data from the US. Nevertheless, some empirical studies challenged these hypotheses [7-12]. According to Berentsen et al. [13], the is a positive association

\footnotetext{
*e-mail: omran@utb.cz

**e-mail: bilan@utb.cz
}

between inflation in the long run. Ho and Iyke [14] found that the relationship is harmful only when the unemployment is less than 5\%. These investigations are in line with the general idea of links between the unemployment rate and economic growth, proved in empirical research in different countries [15-18].

The empirical studies showed different results regarding the relationship between inflation and unemployment in both the short and long- run [19]. According to Hussain and Saaed [20], this relationship varies from one economy to another. Ahiadorme [21] found that the impact of inflation on output and unemployment rate is consistent with the Philips curve predictions and Okun's law in the short run. It should be considered in territorial development planning due to the essential impact of unemployment on their development [22, 23], and appropriate influence on the business environment [24, 25], level of life of the population [26] and widening the gap in employersâĂŹ value proposition [27]. Nevertheless, the new Keynesian Philips curve exists, and Okun's relationship is positive in the long run. Sasongko and Huruta [28] showed that there is a one-way causality between inflation and unemployment. Moreover, unemployment causes inflation, but not viceversa. These patterns may be hidden in terms of the severe informal economy share; however, their impact on inflation and level of life remain in general [29].

Some studies reported an inverse relationship between inflation and the unemployment rate [30-33]. Other studies showed a positive relationship between inflation and the unemployment rate in the long run [13, 19, 34, 35]. Korkmaz and Abdullazade [33] found a trade-off between inflation and the unemployment rate. Mukherjee [32] found an inverse relationship between inflation and the unemployment rate in India. On the contrary, Touny [19] showed a positive relationship between inflation and un- 
employment in Egypt, while Vermeulen [36] found no evidence of the trade-off between inflation and the unemployment rate in the short run.

\section{Methodology}

To investigate the relationship between inflation and employment rate, we applied a three-variables vector autoregressive model (VAR) with the impulse response function (IRF) and time-series data for the period 1980-2019. It was collected from the central bank of Egypt and the world bank table 1 shows the variables of our VAR model.

Table 1. Definition of variables

\begin{tabular}{ll}
\hline Variable & Definition \\
\hline GDP & Log (Real gross domestic product) \\
UNEMP & Log (Unemployment rate \%) \\
INF & Log (Inflation rate\%) \\
\hline
\end{tabular}

According to Sims [37], we can present the VAR model as follows:

$$
\left.Y_{t}=\alpha_{0}+\alpha_{1} y_{(} t-1\right)+\ldots+\alpha_{m} y_{(}(-m)+u_{t}
$$

where:

$\alpha_{i}$ denotes the coefficient matrices;

$y_{t}$ denotes a set the endogenous variables;

$u_{i}$ denotes the stochastic error term for the VAR model.

Therefore, the three variables VAR models can be specified as follows:

$$
\begin{array}{r}
G D P_{t}=\sigma+\sum_{i=1}^{k} \beta_{i} G D P_{t-i}+\sum_{j=1}^{k} \emptyset_{j} U N E M P_{t-j} \\
+\sum_{m=1}^{k} \delta_{m} I N F_{t-m}+u_{1 t} \\
U N E M P_{t}=a+\sum_{i=1}^{k} \beta_{i} G D P_{t-i}+\sum_{j=1}^{k} \emptyset_{j} U N E M P_{t-j} \\
+\sum_{m=1}^{k} \delta_{m} I N F_{t-m}+u_{2 t} \\
I N F_{t}=d+\sum_{i=1}^{k} \beta_{i} G D P_{t-i}+\sum_{j=1}^{k} \emptyset_{j} U N E M P_{t-j} \\
+\sum_{m=1}^{k} \delta_{m} I N F_{t-m}+u_{3 t}
\end{array}
$$

To get the impulse response functions, we set the variables according to Cholesky ordering: we start with $I N F$, then $G D P$, and finally the UNEMP.

Table 2 presents the descriptive statistics of our three variables. To measure the Kurtosis and skewness of each series from the normal distribution, we used the JarqueBera test. The results show that at $1 \%, 5 \%$, and $10 \%$ levels of significance, all the three variables follow the normal distribution.
Table 2. Descriptive statistics

\begin{tabular}{llll}
\hline & GDP & INF & UNEMP \\
\hline Mean & 11.11337 & 1.000868 & 0.955840 \\
Median & 11.13466 & 1.051948 & 0.958406 \\
Maximum & 11.45659 & 1.469919 & 1.119051 \\
Minimum & 10.67888 & 0.355979 & 0.696356 \\
Std. Dev. & 0.228200 & 0.280783 & 0.119838 \\
Skewness & -0.192637 & -0.744492 & -0.738313 \\
Kurtosis & 1.880566 & 2.756127 & 2.755662 \\
\hline Jarque-Bera & 2.277549 & 3.699394 & 3.640206 \\
Probability & 0.320211 & 0.157285 & 0.162009 \\
\hline Sum & 433.4214 & 39.03385 & 37.27776 \\
Sum Sq. Dev. & 1.978867 & 2.995876 & 0.545723 \\
\hline Observations & 39 & 39 & 39 \\
\hline
\end{tabular}

\section{Results}

Before testing our vector autoregressive model (VAR), we want o to make sure that there is no unit root in our variables. To do so, we employ the Augmented Dickey-Fuller test (ADF) at $1 \%, 5 \%$, and $10 \%$ levels of significance. The null hypothesis is that there is a unit root in the variables, meaning that they are nonstationary. Contrarily, the alternative hypothesis is that there is no unit root in the variables, meaning they are stationary. Table 3 shows the augmented dickey fuller test with intercept. AS we can see at levels, all the variables were nonstationary. When we took the first difference, UNEMP and INF became stationary. Furthermore, when we took the second difference, all the variables became stationary.

Table 3. Augmented Dickey-Fuller test (Intercept)

\begin{tabular}{llll}
\hline Variable & P-value & Unit root & Stationary \\
\hline \multicolumn{5}{c}{ Levels } \\
GDP & 0.0321 & Yes & No \\
UNEMP & 0.3095 & Yes & No \\
INF & 0.1806 & Yes & No \\
\hline \multicolumn{5}{c}{ First difference } \\
GDP & 0.1002 & Yes & No \\
UNEMP & 0.0019 & No & Yes \\
INF & 0.0000 & No & Yes \\
\hline \multicolumn{5}{c}{ Second difference } \\
GDP & 0.0000 & No & Yes \\
UNEMP & 0.0000 & No & Yes \\
INF & 0.0000 & No & Yes \\
\hline
\end{tabular}

Table 4 shows an augmented dickey fuller test with the trend and intercept. As we can notice, all the variables were nonstationary at levels. Nevertheless, they became stationary ant the first and second difference. Table 5 shows the augmented dickey fuller test with no trend and intercept, as we can see. All the variables were nonstationary at levels, but they became stationary except GDP when we took the first difference. Nevertheless, taking the second difference converted all the variables to stationary.

Table 6 shows the lag length criterion tests. As we can see, LR, FPE, AIC, SC, and HQ test suggest using one lag in our vector autoregressive model (VAR). 
Table 4. Augmented Dickey-Fuller test with trend and intercept

\begin{tabular}{llll}
\hline Variable & P-value & Unit root & Stationary \\
\hline \multicolumn{4}{c}{ Levels } \\
GDP & 0.9092 & Yes & No \\
UNEMP & 0.2265 & Yes & No \\
INF & 0.4999 & Yes & No \\
\hline \multicolumn{5}{c}{ First difference } \\
GGDP & 0.0635 & No & Yes \\
UNEMP & 0.0131 & No & Yes \\
INF & 0.0000 & No & Yes \\
\hline \multicolumn{5}{c}{ Second difference } \\
GDP & 0.0000 & No & Yes \\
UNEMP & 0.0000 & No & Yes \\
INF & 0.0000 & No & Yes \\
\hline
\end{tabular}

Table 5. Augmented Dickey-Fuller test (no trend and intercept)

\begin{tabular}{llll}
\hline Variable & P-value & Unit root & Stationary \\
\hline \multicolumn{4}{c}{ Levels } \\
GDP & $1.0000 \quad$ Yes & No \\
UNEMP & $0.8150 \quad$ Yes & No \\
INF & 0.3931 & Yes & No \\
\hline \multicolumn{5}{c}{ First difference } \\
GDP & $0.0834 \quad$ No & Yes \\
UNEMP & 0.0000 & No & Yes \\
INF & 0.0000 & No & Yes \\
\hline \multicolumn{5}{c}{ Second difference } \\
GDP & $0.0000 \quad$ No & Yes \\
UNEMP & 0.0000 & No & Yes \\
INF & $0.0000 \quad$ No & Yes \\
\hline
\end{tabular}

Table 7 presents the diagnostics tests for our VAR model. As we can see, there is no serial correlation and Heteroskedasticity in the residuals. Moreover, the model satisfies the normality and stability conditions.

Figure 1 shows the response of each variable to a one standard deviation shock to the inflation rate. We calculated the impulse response function for ten years ahead. The first panel shows the response of GDP to a one standard deviation shock to the inflation rate. As we can see, inflation has a positive impact on GDP. This result is consistent with Semuel and Nurina [38], but it is inconsistent with Faria and Carneiro [39]. When we look at the second panel, we can see that unemployment responds positively to a one standard deviation shock to inflation; there is a trade-off between inflation and the unemployment rate. This result is consistent with Muhammad [40]. Finally, we look at the third panel; we see that inflation responds negatively to a one standard deviation shock.

\section{Conclusion}

The Egyptian monetary policy's main objective is to maintain a low inflation rate in the medium run to keep the confidence and a high rate of investment and economic growth. At the same time, economists argue that targeting a low-rate of inflation may pursue or stifle employment. This article contributes to this debate by investigating the

\section{Response to Cholecky One S.D. (d.f. adjusted) \\ Innovations \pm 2 S.E. Response of GDP to INF}
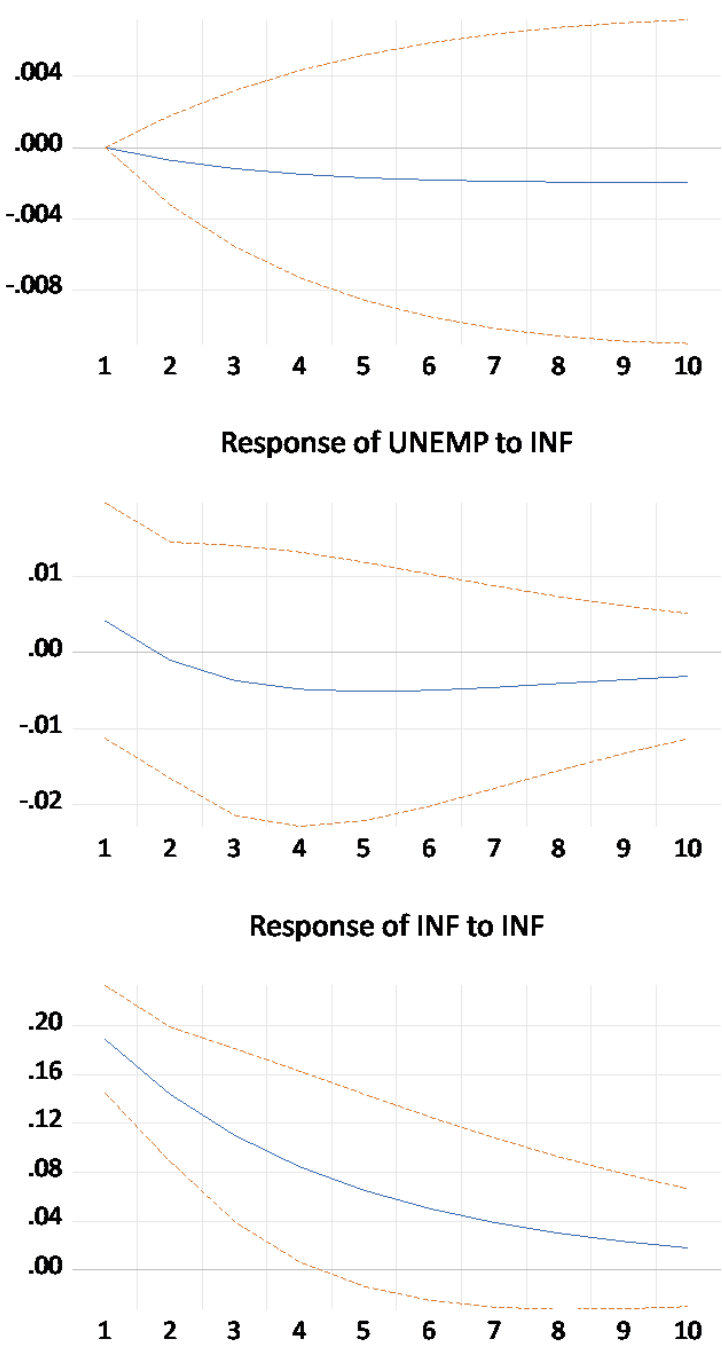

Figure 1. The impulse response functions

relationship between inflation and Egypt's unemployment rate. The authors employed annual time series data from 1980 to 2019, where a vector autoregressive model (VAR) and the Impulse response function tool (IRF) were used. The results show a positive relationship between inflation and GDP, while there is a negative relationship between inflation and the unemployment rate. These results are consistent with the results of Philips [4]. The main recommendations of these results to Egypt's policymakers are that they need to implement their monetary policy considering the unemployment pressures in short-run.

This article was supported by the Internal Grant Agency of Tomas Bata University in Zlin, Project No. IGA/FaME/2021/005, "Significant factors in the sustainability of economic growth with a focus on the SME segment". 
Table 6. Lag length criterion test

\begin{tabular}{lllllll}
\hline Lag & LogL & LR & FPE & AIC & SC & HQ \\
\hline 0 & 44.40942 & NA & $1.63 \cdot 10^{-5}$ & -2.509662 & -2.373615 & -2.463886 \\
1 & 169.8185 & $220.4159^{*}$ & $1.41 \cdot 10^{-8 *}$ & $-9.564755^{*}$ & $-9.020570^{*}$ & $-9.381653^{*}$ \\
2 & 176.9738 & 11.27512 & $1.61 \cdot 10^{-8}$ & -9.452959 & -8.500636 & -9.132531 \\
3 & 185.0917 & 11.31585 & $1.76 \cdot 10^{-8}$ & -9.399498 & -8.039036 & -8.941744 \\
\hline
\end{tabular}

Table 7. Diagnostic tests for the VAR model

\begin{tabular}{lll}
\hline Diagnostic test & Test statistic & P-value \\
\hline Residual Serial Correlation LM Test & 2.328545 & 0.1137 \\
Residual Heteroskedasticity Test & 0.167819 & 0.8462 \\
Stability Test & Satisfied & No roots outside the unit circle. \\
Normality Test (Jargue-Bera) & 0.24032 & 0.886779 \\
\hline
\end{tabular}

\section{References}

[1] A. Suomi, T.P. Schofield, P. Butterworth, Frontiers in Psychology 11, 2745 (2020)

[2] P. Rother, Fiscal policy and inflation volatility (2004), https://www . ecb. europa.eu/pub/pdf/ scpwps/ecbwp317.pdf

[3] F.S. Mishkin, M.A. Savastano, Journal of Development Economics 66, 415 (2001)

[4] A.W. Phillips, Economica 25, 283 (1958)

[5] F. Furuoka, Economics Bulletin 5, 1 (2007)

[6] P.A. Samuelson, R.M. Solow, The American Economic Review 50, 177 (1960)

[7] T.I. Palley, The Manchester School 71, 35 (2003)

[8] A.Ö. Önder, Applied Economics 41, 2597 (2009)

[9] A. da Silva Correa, A. Minella, Revista Brasileira de Economia 64, 231 (2010)

[10] V. Nevena, Industrija 48, 73 (2020)

[11] D. Byrne, Z. Zekaite, Economics Letters 186, $108521(2020)$

[12] K.J. Forbes, J. Gagnon, C.G. Collins, Low inflation bends the phillips curve around the world (2020), https://tinyurl.com/dx2zrhvv

[13] A. Berentsen, G. Menzio, R. Wright, American Economic Review 101, 371 (2011)

[14] S.Y. Ho, B.N. Iyke, The Journal of Developing Areas 53 (2019)

[15] C. Blázquez Fernández, D. Cantarero Prieto, M. Pascual Sáez et al., Economics and Sociology 11, 263 (2018)

[16] H.A. Bobenič, M. Bruothová, Z. Kubíková, R. Ručinskỳ, Journal of International Studies 11, 222 (2018)

[17] O.B. Soylu, I. Çakmak, F. Okur, Journal of International Studies 11, 93 (2018)

[18] A. Widarjono, Economics \& Sociology 13, 203 (2020)

[19] M.A. Touny, International Journal of Economics and Finance 5, 115 (2013)

[20] M.A. Hussain, A.A.J. Saaed, Archives of Business Research 6 (2018)
[21] J.W. Ahiadorme, Macroeconomics and Finance in Emerging Market Economies pp. 1-20 (2021), https://doi .org/10.1080/17520843.2021.1901347

[22] L.Đ. Akimova, N.L. Khomiuk, I.M. Bezena, I.L. Lytvynchuk, O. Petroye, International Journal of Management 11, 567 (2020)

[23] R. Kostiukevych, H. Mishchuk, A. Zhidebekkyzy, J. Nakonieczny, O. Akimov, Economics \& Sociology 13, 46 (2020)

[24] Y. Bilan, H. Mishchuk, I. Roshchyk, O. Joshi, Business: Theory and Practice 21, 780 (2020)

[25] K. Karamanis, C. Beneki, M. Ioakimidis, Journal of International Studies 11, 93 (2018)

[26] H. Mishchuk, N. Samoliuk, Y. Bilan, Administratie si Management Public pp. 63-76 (2019)

[27] Y. Bilan, H. Mishchuk, N. Samoliuk, V. Mishchuk, Entrepreneurial Business and Economics Review 8, 189 (2020)

[28] G. Sasongko, A.D. Huruta, Business: Theory and Practice 20, 1 (2019)

[29] H. Mishchuk, S. Bilan, H. Yurchyk, L. Akimova, M. Navickas, Economics \& Sociology 13, 289 (2020)

[30] A. Wajid, R. Kalim, The impact of inflation and economic growth on unemployment, in Proceedings of 3rd International Conference on Business Management (2013), http://escholar . umt . edu.pk: $8080 /$ jspui/handle/123456789/928

[31] R. Singh, Impact of GDP and Inflation on Unemployment Rate: A Study of Indian Economy in 20112018 8, 329 (2018)

[32] A.K. Mukherjee, International Journal of Educational Research and Development 1, 56 (2019)

[33] S. Korkmaz, M. Abdullazade, Advances in Economics and Business 8, 303 (2020)

[34] A. Orji, I. Orji-Anthony, J. Okafor, Asian Economic and Financial Review 5, 766 (2015)

[35] A. Afonso, H. Şen, A. Kaya, Review of Public Economics 235, 133 (2021)

[36] J.C. Vermeulen, Southern African Business Review 21, 20 (2017)

[37] C.A. Sims, Econometrica 48, 1 (1980) 
[38] H. Semuel, S. Nurina, Analysis of the effect of inflation, interest rates, and exchange rates on Gross Domestic Product (GDP) in Indonesia, in Conference on Global Business, Economics, Finance and Social Sciences, 20-11-2014 - 21-01-2015, Bangkok - Thailand (2014), http://repository.petra.ac.id/
$17008 /$

[39] J.R. Faria, F.G. Carneiro, Journal of applied economics 4, 89 (2001)

[40] M. Shahid, Journal of Economics and Sustainable Development 5, 1 (2014) 